\title{
Colour Mixing and Colour Preferences in Neonate Gulls
}

Spontaneous colour preferences of neonate herring gulls (Larus argentatus) were demonstrated by TINBER$\triangle E N$ and PERDECK ${ }^{1}$ in a classic study exemplifying an innate releasing mechanism. When begging for food gull chicks peck at the tip of their parent's beak, a behaviour to which the adults respond by regurgitation. In an experimental situation the chicks will, if hungry, peck at small sized, moving chromatic stimuli that simulate to some extent the parent's bill. The response frequency depends on, among parameters, the hue of the stimuli.

One of us $^{2}$ recently reinvestigated these experience independent colour preferences of herring and lesser blackbacked gulls (Lanus fuscus) using patches of narrow-band, nearly monochromatic spectral light as stimuli. Experiments were carried out within which the light intensity of the stimuli was adjusted either to equal physical energy or:

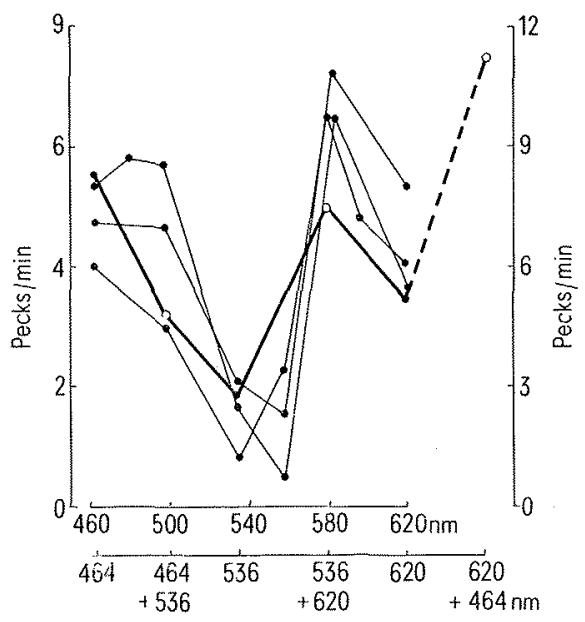

Fig. 1. The response of neonate gulls to spectral and mixed light stimuli. Present experiment: heavy line, lower and left scales. Thin lines, upper and right scales: earlier experiments². to equal physiological effectiveness according to electroretinographic spectral sensitivity criteria ${ }^{3}$. Part of the results of these experiments are presented in Figure 1. There are two preference peaks. One is in the red-yellow region of the spectrum and may be related to the colour of the parental beak (yellow with a red patch); the other peak in the blue region cannot be easily explained in functional terms ${ }^{4}$. Similar chromatic preference patterns are shown by these gulls in some other behaviour contexts ${ }^{2}$ and also by other larid and non-larid species ${ }^{5-9}$.

Two models conceived as peripheral filtering mechanisms ${ }^{10}$ have been proposed to account for this response spectrum. As will be described later they make definite predictions for the case where the animals respond to mixtures of spectral lights and the following experiment was designed to test these.

We employed an apparatus similar to that used in the earlier experiments ${ }^{2}$. Two oscillating light spots projected on a ground glass wall of a small arena were the stimuli. Each was $8 \mathrm{~mm}$ in diameter, they were separated by $3 \mathrm{~cm}$, and moved $5 \mathrm{~mm}$ from side to side once every second. The spectral composition and the luminance of each stimulus was controlled with 3 independent optical projection systems. Three interference filters with halfband widths of $10 \mathrm{~nm}$ provided spectral lights of $464 \mathrm{~nm}$ (blue), $536 \mathrm{~nm}$ (green) and $620 \mathrm{~nm}$ (red) wavelength. Their intensity was equated for physiological effectiveness in terms of the electroretinographic spectral sensitivity of juvenile

1. N. Tinbergen and A. C. Perdek, Behaviour 3, 1 (1950).

${ }^{2}$ G. Thompson, Ph. D. Thesis, Oxford University (1970).

${ }^{3}$ G. Trompson, Vision Res. 17, 719 (1971).

J. P. Harlana, Science 162, 139 (1968).

5 E. H. Hess, Psychol. Rep. 2, 477 (1956).

${ }^{6}$ U. Werduan, Anim. Behav. 9, 115 (1961).

${ }^{7}$ D. A. QUiNe and J. M. CulleN, Ibis 706, 145 (1964).

8 J. P. HaILMAN, Behaviour, Suppl. 15, 1 (1967).

a M. Nyström, $Z$. Tierpsychol. 30, 36 (1972).

10 P. Marter, Current Problems of Animal Behavionr (Eds. W. H. Thorpe and O. L. Zangwhl, Cambridge University Press 1961).
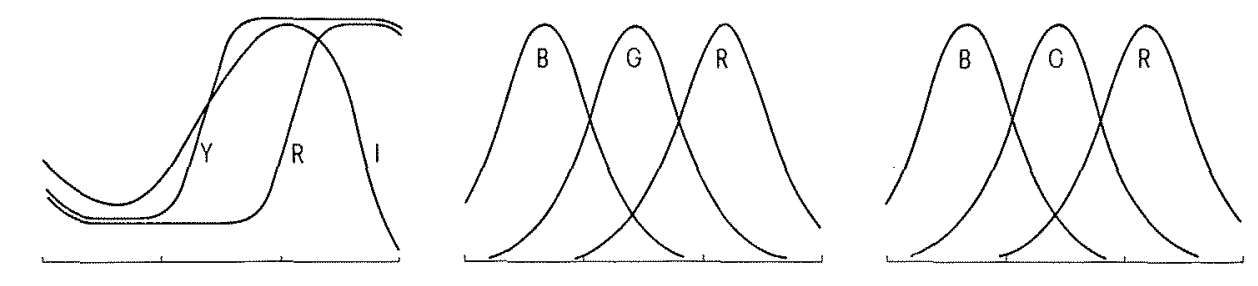

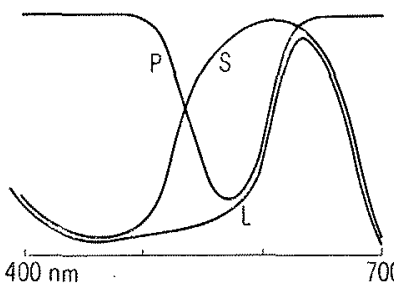

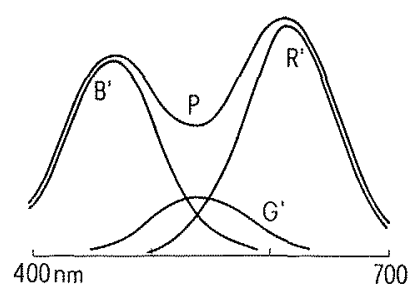

B

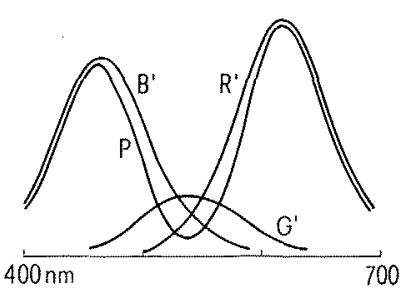

$\mathrm{C}$

Fig. 2. Three models for the colour preference mechanism of neonate gulls (schematic). A) I $(\lambda)$ absorption of cone pigment; $Y(\lambda)$ and $\mathrm{R}(\lambda)$, transmission of yellow and red cone oildroplets; $S(\lambda)=I(\lambda) \times Y(\lambda)$, and $L(\lambda)=I(\lambda) \times R(\lambda)$ effective sensitivity of yellow and red droplet bearing cones; $\mathrm{P}(\hat{\lambda})=S(\lambda) / \mathrm{L}(\lambda)$ response spectrum resulting through inhibition by division. $\mathrm{B}) \mathrm{B}(\hat{\lambda}), \mathrm{G}(\lambda)$ and $\mathrm{R}(\lambda)$ sensitivity of retinal modulators. $\mathrm{B}^{\prime}(\lambda)=\mathrm{B}(\lambda) \times \mathrm{k}, \mathrm{G}(\lambda)=\mathrm{G}^{\prime}(\lambda) \times \mathrm{j}$ and $\mathrm{R}^{\prime}(\lambda)=\mathrm{R}(\lambda) \times \mathrm{i}$ where $\mathrm{j} \ll \mathrm{k}<\mathrm{i}$, effective sensitivity of colour mechanisms after differential amplification, $\mathrm{P}(\lambda)=\mathrm{B}^{\prime}(\lambda)+\mathrm{G}^{\prime}(\lambda)+\mathrm{R}^{\prime}(\lambda)$ response spectrum resulting through summation. $\left.\mathrm{C}\right) \mathrm{B}(\lambda)$, $\mathrm{G}$ $(\lambda), \mathrm{R}(\lambda), \mathrm{B}^{\prime}(\hat{\lambda}), \mathrm{G}^{\prime}(\lambda)$ and $\mathrm{R}^{\prime}(\lambda)$ as in model $\mathrm{B}, \mathrm{P}(\lambda)=\mathrm{B}^{\prime}(\lambda)+\mathrm{R}^{\prime}(\lambda)-\mathrm{G}^{\prime}(\lambda)$ response spectrum resulting through summation and stbstractive inhibition. 
Table I. The response of neonate gulls to 3 spectral and 3 mixed light stimuli

\begin{tabular}{|c|c|c|c|}
\hline & Red & - Green & Blue \\
\hline & - & 1.7 & 5.8 \\
\hline \multirow{2}{*}{ Green + blue } & - & 5.2 & 1.1 \\
\hline & $\begin{array}{l}4.4 \\
6\end{array}$ & - & 5.2 \\
\hline Red + blue & 7.4 & - & 7.8 \\
\hline . & 2.5 & 1.7 & - \\
\hline Red + green & 4.2 & 5.7 & - \\
\hline
\end{tabular}

Mean response rates $(n=12)$ in pecks per min to 6 stimulus pairs $a, 0$ Differences significant at $p<0.05$ and $p<0.01$, Wilcoxon test

gulls ${ }^{3}$. The luminance of the $536 \mathrm{~nm}$ stimulus was approximately $1.4 \log \mathrm{ft}$. lambert. Three non-spectral mixed hues, red-green, green-blue and blue-red, were obtained by superimposing pairs of these spectral lights without attenuation. Internally reflecting tubes ensured a homogeneous mixing.

As it was technically not possible to compare pairs of mixed coloured lights simultaneously and the responsiveness to the pure spectral lights when shown in pairs was well established, the mixed colours were presented simultaneously with one or the other of their component spectral colours. In a randomized sequence of trials incorporating stimulus side reversals, the 6 pairs of stimuli were presented 12 times to 15 two- to three-day-old incubatorhatched herring and lesser black-backed gull chicks. The chicks were not exposed to any strongly chromatic stimuli except in the test situation. For each trial a chick was placed in the experimental arena for $1 \mathrm{~min}$ and its responses to the stimuli were recorded with 2 microswitches linked to electromechanical counters. On a few cases where a chick refused to peck the trial was repeated with another chick.

The results are presented in Table $I$ and summarized in Figure 1. Apart trom a slightly lower response rate the response pattern to the 3 spectral lights agrees with that found in earlier experiments.

We now describe the models mentioned earlier. One of them (A) originally devised to account for the pecking preferences of laughing gull (Larus atricilla) chicks, ${ }^{8}$, is based on the assumption that birds only possess a single cone pigment 11 and that their coloured cone oildroplets are responsible for the differential spectral sensitivities of populations of cones ${ }^{12}$. Figure $2 \mathrm{~A}$ summarizes the model. A linear version of the model has very similar properties and a later suggestion that the green oildroplet bearing cones act synergistically with the yellow oildroplet mechanism ${ }^{13}$ does not materially affect the present discussion.

The other model (B) was originally proposed to deal with the preferences of herring gull chicks when approaching coloured surfaces ${ }^{14}$. It is based on the assumption that gulls have retinal mechanisms sensitive to 3 different narrow spectral ranges corresponding to DONNER's pigeon modulators ${ }^{15}$. These could in turn depend on the existence of 3 cone pigments or a complex interaction of cones with a single photopigment, but bearing different oildroplets ${ }^{3}$. Figure $2 \mathrm{~B}$ presents this model. The original version incorporated some additional features but these are inmaterial in the present context.
Table II. Comparative response strength predictions for spectral lights and their mixtures of models $A, B$ and $C$.

\begin{tabular}{lllll}
\hline $\begin{array}{l}\text { Model } \\
\text { Mixture }\end{array}$ & $\mathrm{A}$ & $\mathrm{B}$ & $\mathrm{C}$ & Empirical \\
\hline $\mathrm{G}+\mathrm{B}$ & $=\mathrm{G}$ & $>\mathrm{G}$ & $>\mathrm{G}$ & $>\mathrm{G}$ \\
& $<\mathrm{B}$ & $>\mathrm{B}$ & $<\mathrm{B}$ & $<\mathrm{B}$ \\
$\mathrm{R}+\mathrm{B}$ & $=\mathrm{R}$ & $>\mathrm{R}$ & $>\mathrm{R}$ & $>\mathrm{R}$ \\
& $=\mathrm{B}$ & $>\mathrm{B}$ & $>\mathrm{B}$ & $\geq \mathrm{B}$ \\
$\mathrm{R}+\mathrm{G}$ & $<\mathrm{R}$ & $>\mathrm{R}$ & $<\mathrm{R}$ & $>\mathrm{R}$ \\
& $=\mathrm{G}$ & $>\mathrm{G}$ & $>\mathrm{G}$ & $>\mathrm{G}$ \\
\hline
\end{tabular}

A third, unpublished model (C) related to the one just discussed has also been considered. It is similarly based on DONNER's modulators and is summarized in Figure $2 \mathrm{C}$.

Table II lists the predictions that the 3 models make regarding the responsiveness of gull chicks to mixtures of spectral lights compared to the response to the component lights alone.

It will be noticed that none of the models fits the empirical data satisfactorily. Nodel A does not concord with a number of results, model $\mathrm{B}$ fails on the green-blue mixture and model $\mathrm{C}$ does not predict the red-green results correctly. Thus none of the models is adequate. While it may be possible to tailor a specific filtering model to deal with our data we wonder whether this is a profitable approach. For human observers the red-green and the greenblue light mixtures used matched the hue of, respectively, a spectral yellow of $580 \mathrm{~nm}$ and a spectral blue-green of $500 \mathrm{~nm}$. The chicks responded to the mixtures as if the same matches were correct for them in that their levels of responding to the mixtures were similar to those they gave to the corresponding spectral stimuli in earlier experiments (Figure 1).

This observation that gull chicks appear to obey colour mixing laws similar to our own ${ }^{16}$, in conjunction with the known colour dicrimination capabilities of birds ${ }^{17}$ suggest that the colour preferences of gull chicks are not due to the action of an afferent, behaviour specific filter, but rather to a response specific, hue weighting mechanism that is efferent to perceptual mechanisms primarily designed for the recognition of hues independently of the behavioural context 18

Zusammenfassung. Junggeschlïpfte Silber- und Heringsmöven zeigen beim Picken von kleinflächigen, bewegli-

11 C. D. B. Bridges, Vision Res. 2, 125 (1962).

12 G. K. Strother, Expl. Cell Res. 29, 349 (1963).

13 J. P. Haxman, Experientia 22, 257 (1966).

14 J. D. Delues and G. Thompson, Z. Tierpsychol. 27, 842 (1970).

15 K. O. Donser, J. Physiol., Lond. 122, 524 (1953)

${ }^{16}$ T. N. Cornsweer, Visual Perception (Academic Press, New York 1970).

17 W. F. Hamlon and T. B. Colenan, J. comp. Psychol. 75, 183 (1933).

18 The work has been supported by a grant from the Science Research Council (London). The help of departmental technicians is gratefully acknowledged. 
chen Reizen Spektralfarbbevorzugungen. Drei theoretische Modelle sind vorgeschlagen worden, die diese Bevorzugungen erklären sollen. Die Voraussagen dieser Modelle bezüglich der Bevorzugung von Mischfarben wurden experimentell geprüft und als nicht zutreffend befunden. Vielmehr legen die Ergebnisse die Vermutung nahe, dass die Bevorzugung nicht, wie bisher angenommen, auf einem afferenten sensorischen Filtermechanismus beruht, sondern auf einen mehr zentralen, postperzeptualen Prozess zurückzuführen ist.

Juan D. Deluus, Grllian Thompson, KetTh L. AlLEN and JAcKY EMmerton

Department of Psychology, University of Durham,

Durham (England), and Department of Zoology,

University of Reading, Reading (England), 18 April 1972. 